\title{
Atmospheric Test Models and Numerical Experiments for the Simulation of the Global Distribution of Weather Data Transponders
}

\author{
A.S. Grossman, C.R. Molenkamp
}

August 25, 1999

U.S. Department of Energy

Lawrence

Livermore

National

Laboratory

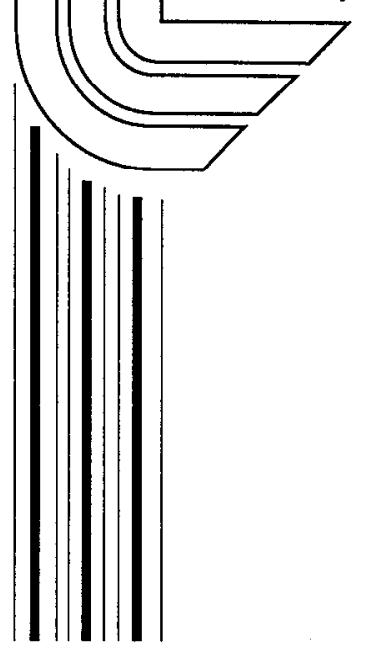




\section{DISCLAIMER}

This document was prepared as an account of work sponsored by an agency of the United States Government. Neither the United States Government nor the University of California nor any of their employees, makes any warranty, express or implied, or assumes any legal liability or responsibility for the accuracy, completeness, or usefulness of any information, apparatus, product, or process disclosed, or represents that its use would not infringe privately owned rights. Reference herein to any specific commercial product, process, or service by trade name, trademark, manufacturer, or otherwise, does not necessarily constitute or imply its endorsement, recommendation, or favoring by the United States Government or the University of California. The views and opinions of authors expressed herein do not necessarily state or reflect those of the United States Government or the University of California, and shall not be used for advertising or product endorsement purposes.

Work performed under the auspices of the U. S. Department of Energy by the University of California Lawrence Livermore National Laboratory under Contract W-7405-Eng-48.

This report has been reproduced directly from the best available copy.

Available to DOE and DOE contractors from the Office of Scientific and Technical Information

P.O. Box 62, Oak Ridge, TN 37831

Prices available from (423) 576-8401 http://apollo.osti.gov/bridge/

Available to the public from the National Technical Information Service

U.S. Department of Commerce 5285 Port Royal Rd., Springfield, VA 22161 http://www.ntis.gov/

OR Lawrence Livermore National Laboratory Technical Information Department's Digital Library http://www.llnl.gov/tid/Library.html 
Atmospheric Test Models and Numerical Experiments for the Simulation of the Global Distribution of Weather Data Transponders

\author{
Allen S. Grossman \\ and \\ Charles R. Molenkamp \\ Atmospheric Science Division \\ Lawrence Livermore National Laboratory
}

\begin{abstract}
A proposal has been made to establish a high density global network of atmospheric micro transponders to record time, temperature, and wind data with time resolution of $\leq 1$ minute, temperature accuracy of $\pm 1^{\circ} \mathrm{K}$, spatial resolution no poorer than $\sim 3 \mathrm{~km}$ horizontally and $\sim 0.1 \mathrm{~km}$ vertically, and $2-\mathrm{D}$ speed accuracy of $\leq 1 \mathrm{~m} / \mathrm{s}$. This data will be used in conjunction with advanced numerical weather prediction models to provide increases in the reliability of long range weather forecasts. Major advances in data collection technology will be required to provide the proposed high-resolution data collection network. Systems studies must be undertaken to determine insertion requirements, spacing, and evolution of the transponder ensemble, which will be used to collect the data. Numerical models which provide realistic global weather pattern simulations must be utilized in order to perform these studies. A global circulation model with a $3^{\circ}$ horizontal resolution has been used for initial simulations of the generation and evolution of transponder distributions. These studies indicate that reasonable global coverage of transponders can be achieved by a launch scenario consisting of the sequential launch of transponders at specified heights from a globally distributed set of launch sites.
\end{abstract}




\section{A. INTRODUCTION}

Advanced numerical weather prediction models are being used with ever increasing spatial resolution. For these models to provide the anticipated improvement in forecast accuracy and range, major advances are needed in the atmospheric observation system. High-resolution observations are required on the same scale as the global models to provide for initialization, data assimilation, and validation of weather forecasts. Teller et al. (1998) propose to establish a high density global network of atmospheric micro transponders to record time, temperature and wind data with time resolution of $\leq 1$ minute, temperature accuracy of $\pm 1^{\circ} \mathrm{K}$, spatial resolution no poorer than $\sim 3 \mathrm{~km}$ horizontally, and $\sim 0.1 \mathrm{~km}$ vertically, and $2-\mathrm{D}$ speed accuracy of $\leq 1 \mathrm{~m} / \mathrm{s}$. This will require the development of advanced numerical models, which utilize these data fields, to perform accurate weather predictions. The proposal discusses the requirements for very highresolution prognostic models, which would take advantage of the capabilities of the new generation of multi-tera flop computers under development at the DOE laboratories. These models will have resolutions of approximately $1 \mathrm{~km} \times 1 \mathrm{~km}$ horizontally and $0.1 \mathrm{~km}$ vertically to an altitude of $20 \mathrm{~km}$ above the Earth's surface. Using projected computer processing capacities, such a model could produce numerical weather predictions $10 \mathrm{X}$ faster than real time by the year 2002 and $1000 \mathrm{X}$ faster than real time by the year 2010 . Complementing the model development, a constellation of $\sim 10^{10}$ micro-transponders would be placed in the atmosphere to record the data which would be used to initialize the prognostic models.

At the present time, existing General Circulation Models (GCM's) have horizontal resolutions on the order of 1 - 3 degrees in latitude and longitude, 16 vertical levels between the surface and $\sim 3 \mathrm{mb}$, and time steps on the order of 1000 seconds. Regional prognostic models have horizontal resolutions on the order of $1-10 \mathrm{~km}, 40$ vertical levels between the surface and $\sim 15 \mathrm{~km}$ altitude, and time steps on the order of 5 seconds. The current model development strategies are just beginning to take advantage of massively parallel computer architectures. DOE and LLNL, via their advanced Environmental Science and Computing initiatives, are attempting to close the resolution gap between the regional and global models by supporting the development of the next generation of very high resolution global models. The Atmospheric Science Division is currently using the NCAR (National Center for Atmospheric Research) CCM3 GCM as well as the NRL (Naval Research Laboratory) COAMPS Regional Prognostic Model for application studies in the area of global climate change and regional studies of the atmospheric transport and fate of hazardous materials. These models are being ported to the current ASCI machines.

Initial systems studies will be performed to aid the transponder development team in the systems planning for optimal transponder insertion, location, drift, and lifetime scenarios. We will be working with the global model development teams (LLNL - LANL NCAR - NASA) to use the next generation of very high resolution GCM's, as they become available, for advanced systems studies. We will also work with groups at NCEP and NRL to coordinate efforts in application studies of the use of high-resolution observational data sets into numerical weather prediction schemes.

\section{B. LONG RANGE NUMERICAL WEATHER PREDICTION}

Daley (1991) cites two conditions, which must be satisfied to provide a successful prediction of a future atmospheric state: 
I. The present state of the atmosphere must be determined as accurately as possible.

II. The governing equations and laws of physics from which future states develop from preceding states must be known.

Daley (1991) discusses the international weather observational system as it existed in 1989, and it shows large areas of the globe with sparse observational data collection points. Satellite based temperature measurements have resolutions on the order of $250 \mathrm{~km}$ horizontally, $200 \mathrm{mb}$ in altitude $(\sim 2 \mathrm{~km}$ near the surface to $\sim 7 \mathrm{~km}$ at the tropopause) and errors of $2-3^{\circ} \mathrm{K}$. Our proposed temperature resolution is $\sim 0.1 \mathrm{~km}$ vertically, $\sim 1 \mathrm{~km}$ horizontally, and errors of $\sim 1^{\circ} \mathrm{K}$. Current surface station observations are irregularly distributed over land and well traveled shipping lanes and provide temperatures to $1{ }^{\circ} \mathrm{K}$ accuracy and horizontal winds to $\sim 3 \mathrm{~m} / \mathrm{s}$ accuracy. High altitude wind $(200 \mathrm{mb})$ observations, obtained by aircraft and satellite based cloud drift data, and low altitude wind observations are irregularly spaced and have accuracies on the order of 3 $-5 \mathrm{~m} / \mathrm{s}$. Our proposed wind data resolution is $\sim 0.1 \mathrm{~km}$ vertically, $\sim 1 \mathrm{~km}$ horizontally, and errors of $\sim 1 \mathrm{~m} / \mathrm{s}$. Lorenz and Emanual (1998) show that for simplified models, significant increases in the 5 - 10 day forecast skill can be made by increasing the observational data base in sparsely sampled regions. Our proposed global, very high-resolution observational database should provide enough coverage to yield data over the sensitive areas, which limit forecast accuracies.

Lorenz (1969) considered the question of the predictability of the atmosphere and concluded that the range of predictability of the atmosphere, given the accuracy in the observations of the state of the atmosphere at that time and the details of the prognostic models, to be about two weeks. Leith (1974), using estimated, observational resolution achievable in the $1980^{\prime} \mathrm{s}$, developed a Monte Carlo procedure which improved forecast skills of the models in the 6 - 10 day range. Holton (1986) concludes that the meteorological community has expectations of useful forecasts of the detailed structure of the general atmospheric circulation for periods out to between 7 and 14 days. Ensemble model forecasting techniques (Toth and Kalnay, 1993; Tracton, 1993; Houtekamer and Derome, 1995) allow skill scores between about $20 \%$ and $70 \%$ for forecast lengths of up to two weeks depending on the area, season and forecast variable. Skill scores are defined as $100 \%$ for perfect forecasts and $0 \%$ for forecasts, which are only as good as the reference climatology (Roebber and Bosart, 1996). Adaptive adjoint model techniques applied to NWP (numerical weather prediction) models (Gelaro et al., 1998) result in skill scores on the order of $10 \%$ to $70 \%$ for 5 - 10 day forecasts of the $500 \mathrm{mb}$ geopotential height over the northern hemisphere. The next generation of climate models being developed will have $\sim 10 \mathrm{~km}$ horizontal resolution and $\sim 40$ vertical levels as well as a coupled ocean model. This increased resolution over the current generation of NWP models will allow inclusion of more detailed smaller scale processes and should provide improved forecasts in the $10-14$ day time range. Further improvements in computing power will allow higher model resolutions to $1 \mathrm{~km}$ horizontally and $0.1 \mathrm{~km}$ vertically. These improved model capabilities when coupled with the proposed high-resolution observational data base will yield substantially increased forecast skill scores in all regions the globe.

\section{INITIAL SYSTEMS STUDIES FOR THE TRANSPONDER ENSEMBLE}

In addition to the major advances in data collection technology required to provide the proposed high resolution data collection network, important systems studies must be undertaken to determine insertion requirements, spacing, and evolution of the transponder ensemble. Two of the most important questions that need to be investigated are: 
1. From an operational perspective, what launch scenarios need to be employed to establish and maintain a global distribution of transponders.

2. What density, information, and frequency of observations are optimal and useful for the next generation of NWP models to provide more accurate long range weather predictions.

In order to perform these studies, numerical models that provide realistic global weather pattern simulations must be utilized. This requires the use of a global circulation model (GCM) to provide atmospheric wind flow patterns coupled to a transport model to provide transponder trajectories. Transponder insertion scenarios can then be studied to provide optimal insertion locations and rates as well as resulting ensemble distribution, and spacing data. 'The first issues to be addressed were:

1. Will an initial, uniform global distribution of transponders retain reasonable global coverage after a thirty-five day time period.

2. Will transponders released at a pre-determined number of levels, at daily intervals, from a set of selected launch sites, provide a reasonable global distribution after a thirty-five day time period.

The initial studies use the NCAR CCM3 GCM (Kiehl et al., 1996) to provide the horizontal wind fields at each grid point of a $2.8^{\circ} \times 2.8^{\circ}$ (latitude-longitude) $\mathrm{x} 18$ vertical level global grid at four hour time intervals for a period of 35 days. These wind fields were used to drive the LLNL GRANTOUR chemistry-transport model (Walton et al., 1998). GRANTOUR is a Lagrangian parcel model in which the atmosphere is treated as a set of constant mass air parcels advected by GCM wind fields on a fixed Eulerian grid. For the simulations performed in this paper, each parcel was taken to be a transponder and parcel chemistry was turned off. The above grid gives 8192 transponders at each vertical level. Each transponder in the constellation is envisioned as a small $(\sim 10 \mathrm{~cm}$ diameter $)$ free floating, neutrally buoyant, balloon with inflation pressures and gases designed to keep the balloon at a fixed, designated atmospheric pressure level. For the initial simulations it is assumed that the balloons are constrained to fixed pressure levels and vertical motions neglected. Sample calculations based on the balloon equation of motion given by Hanna and Hoecker (1971) for small, high drag coefficient balloons of the type we envision, show that the balloons should be tightly coupled to the designated pressure levels even for relatively high vertical air velocities.

The results of the Study 1 above are shown in Figures $1-7$. Figure 1 shows the initial, uniform, balloon distribution at each $\sigma$ level $(\mathrm{P} / 1000 \mathrm{mb})$ in the atmosphere. $\sigma$ levels of $0.925,0.85,0.775,0.7,0.6,0.5,0.4,0.3$, and 0.2 were used in the calculations. Figures $2-4$ show the balloon distributions at $\sigma=0.775(\sim 2 \mathrm{~km}$ altitude $)$ after 1,10 and 35 days. Figures $5-7$ show the balloon distributions at $\sigma=0.200(\sim 11.5 \mathrm{~km}$ altitude $)$ after 1, 10 and 35 days. The figures show that the 35-day balloon distributions still provide reasonable global coverage.

The results of Study 2 above are shown in Figures 8 - 10. A suite of 306 balloon launch sites were chosen to provide global coverage with the condition that there be a land mass available at the site for a launch platform. Figure 8 shows the map of launch sites. At each launch site, balloons were released at a rate of 1 balloon per day, at each $\sigma$ level, for the 35-day time period. Figures 9 and 10 show the balloon distributions at $\sigma=0.775$ and 0.200 after 35 days. The figures show that the 35 -day balloon distributions provide reasonable global coverage similar to that calculated above.

The trajectory calculations performed in this paper can be compared to actual balloon trajectories measured by the GHOST Balloon Project (Lally and Lichfield, 1969). 
A series of 200 balloon flights were made in the Southern Hemisphere with superpressure balloons at altitudes of $\sim 900 \mathrm{mb}$ to $\sim 30 \mathrm{mb}$. A set of trajectories for a $200 \mathrm{mb}$ altitude balloon launched from Christchurch, New Zealand is shown in Figure 11. The trajectories for 8 orbits are approximately circular and have an average period of about 12.5 days. As a validation of the CCM3-GRANTOUR balloon trajectory model, calculations of $200 \mathrm{mb}$ balloon trajectories were made for a balloon launched from Christchurch on three successive days. The results are shown in Figures12 -14. The average orbital period for the calculated balloon trajectory is approximately 10 days and the extent of the orbits is in good agreement with the experimental results.

In addition to the trajectory measurement, the GHOST Balloon Project gave the set of atmospheric balloon lifetimes shown in Table 1.

Table 1.

GHOST Project Balloon Lifetimes

$\begin{array}{ccc}\text { Altitude }(\mathrm{mb}) & \text { Lifetime (days) } & \text { Factor } \\ 700 & \sim 14 & \text { super-cooled water accumulation } \\ 500 & 7-10 & \text { super-cooled water accumulation } \\ 400 & \sim 15 & \text { super-cooled water accumulation } \\ 300 & 30-40 & \text { ice crystal accumulation } \\ 200 & \sim 150 & \text { ice crystal accumulation }\end{array}$

These data, along with the CCM3 GCM convective and large-scale precipitation fields, can be used to develop a balloon lifetime parameterization which could be incorporated into future balloon scenario simulations.

Future balloon simulation scenarios will include; 1) extension of the above calculations to a full annual cycle, 2) incorporation of large scale vertical velocities derived from the CCM3 GCM horizontal velocity fields, coupled to a parameterized balloon equation of motion, to allow simulation of the effects of surface release of the balloons and vertical motions on the resulting global balloon distributions, 3) finite balloon lifetime effects, and 4) localized balloon dispersion effects using nested CCM3-COAMPS (regional prognostic model) wind fields.

Another important study will be to understand how different distributions of the transponder ensemble will affect forecasts. We envision taking a high resolution GCM run over a period of two weeks as a "truth" simulation. The next step will be to perform simulations of the kind performed by Lorenz and Emanual (1998), for a simple atmospheric analog, in which full GCM forecast runs would be made for cases which have varying degrees of incomplete initial grid point data. The object will be to determine the relation between the number and location of transponders needed to produce a forecast with a particular skill score. These exercises will allow cost-benefit studies of transponder numbers and deployment scenarios to be made. As in the cases discussed above, initial studies will be made with the CCM3 GCM and advanced studies will be made with the newer high resolution GCM's currently being developed. We will also address the question of whether increases in resolution of the GCM models change the optimal systematics and requirements of the transponder ensembles, which were calculated using lower resolution models. Increased model resolution will lead to more detailed models of 
small-scale processes which, in turn, may change the predictability of the forecast models. This will lead to increased data resolution requirements.

The proposed data collection network will require a new look at data assimilation techniques for the next generation of NWP models given the quantity of data to be collected with the proposed network and the model initialization requirements. We propose to establish collaborations with groups at NRL as well as NCEP (National Center for Environmental Prediction) to determine the best methods for data assimilation to provide the most efficient use of the high-resolution data.

This work was performed under the auspices of Lawrence Livermore National Laboratory via the Laboratory Directed Research and Development (LDRD) Program and the U. S. Dept. of Energy under contract No. W-7405-Eng-48.

\section{REFERENCES}

Daley, R., 1991: Atmospheric Data Analysis, Cambridge University Press, Cambridge, Eng.

Gelaro, R., R. Buizza, T. N. Palmer, and E. Klinker, 1998: Sensitivity Analysis of Forecast Errors and the Construction of Optimal Perturbations Using Singular Vectors, J.Atm.Sci., 55, pp 1012 -1035.

Hanna, S. R., and W. H. Hoecker, 1971: The response of constant-density balloons to sinusoidal variations of vertical wind speeds, J. App. Met., 10, pp $601-604$.

Holton, J. T., 1986: The Physics Of Atmospheres, Cambridge University Press, Cambridge, Eng.

Houtekamer, P. L., and J. Derome, 1995: Methods for Ensemble Prediction, Monthly Weather Review, 123, pp 2181 - 2196.

Keihl, J. T., J. J. Hack, G. B. Bonan, B. Y. Boville, B. P. Briegleb, D. L. Williamson, and P. J. Rash, 1996: Description of the NCAR community climate model (CCM3). NCAR Tech. Note. NCAR/TN-420+STR.

Lally, V. E., and E. W. Lichfield, 1969: Summary of status and plans for the GHOST balloon project, Bull. Amer. Met. Soc., 50, pp867-864.

Leith, C. E., 1974: Theoretical Skill of Monte Carlo Forecasts, Monthly Weather Review, 102 , pp $409-418$.

Lorenz, E. N., 1969: The Predictability of a Flow Which Possesses Many Scales of Motion, Tellus, 21, pp 289 - 307.

Lorenz, E. N., and K. A. Emanuel, 1998: Optimal Sites for Supplementary Weather Observations: Simulation With a Small Model, J.Atm.Sci., 55, pp 399 - 414.

Roebber, P. J., and L. F. Bosart, 1996: The Complex Relationship Between Forecast Skill and Forecast Value: A Real-World Analysis, Weather and Forcasting, 11, pp 544

- $\quad 559$. 
Teller, E., L. Wood, R. Hyde, M. Ishikawa, A. Ledebuhr, C. Leith, J. Nuckolls, and G. Canavan, 1998: Long Range Weather Predictions Enabled by Probing of the Atmosphere at High Space Time Resolution. LLNL Report UCRL-JC-131601.

Toth, Z., and E. Kalney, 1993: Ensemble Forcasting At NMC: The Generation of Perturbations, Bull. Amer. Meteor. Soc., 74, pp 2317 - 2330.

Tracton, M., S., 1993: On the Skill and Utility of NMC's Medium Range Central Guidance, Weather and Forcasting, 8, pp 147 - 153.

Walton, J. J., M. C. MacCracken, and S. J. Ghan, 1988: A global-scale Lagrangian trace species model of transport, transformation, and removal process, J. Geophys. Res., 93, pp 8339 - 8354. 


\section{Figure Captions}

Figure 1. Distribution of transponders at each pressure level as a function of latitude and longitude for the uniform initial distribution case.

Figure 2. Distribution of transponders at the $775 \mathrm{mb}$ pressure level after 1 day as a function of latitude and longitude for the uniform initial distribution case.

Figure 3. Distribution of transponders at the $775 \mathrm{mb}$ pressure level after 10 days as a function of latitude and longitude for the uniform initial distribution case.

Figure 4. Distribution of transponders at the $775 \mathrm{mb}$ pressure level after 35 days as a function of latitude and longitude for the uniform initial distribution case.

Figure 5. Distribution of transponders at the $200 \mathrm{mb}$ pressure level after 1 day as a function of latitude and longitude for the uniform initial distribution case.

Figure 6. Distribution of transponders at the $200 \mathrm{mb}$ pressure level after 10 days as a function of latitude and longitude for the uniform initial distribution case.

Figure 7. Distribution of transponders at the $200 \mathrm{mb}$ pressure level after 35 days as a function of latitude and longitude for the uniform initial distribution case.

Figure 8. Latitude-longitude map of transponder release sites for the 306 launch site, daily release study.

Figure 9. Distribution of transponders at the $775 \mathrm{mb}$ pressure level after 35 days as a function of latitude and longitude for the 306 launch site, daily release study.

Figure 10. Distribution of transponders at the $200 \mathrm{mb}$ pressure level after 35 days as a function of latitude and longitude for the 306 launch site, daily release study.

Figure 11. Polar view of the measured trajectories of the GHOST Project balloons released at the $200 \mathrm{mb}$ pressure level from Christchurch New Zealand.

Figure 12. Polar view of the calculated trajectory of a transponder released at the $200 \mathrm{mb}$ pressure level from Christchurch New Zealand on day 1.

Figure 13. Polar view of the calculated trajectory of a transponder released at the $200 \mathrm{mb}$ pressure level from Christchurch New Zealand on day 2.

Figure 14. Polar view of the calculated trajectory of a transponder released at the $200 \mathrm{mb}$ pressure level from Christchurch New Zealand on day 3. 
Distribution of transponders at each pressure level as a function

of latitude and longitude for the uniform initial distribution case

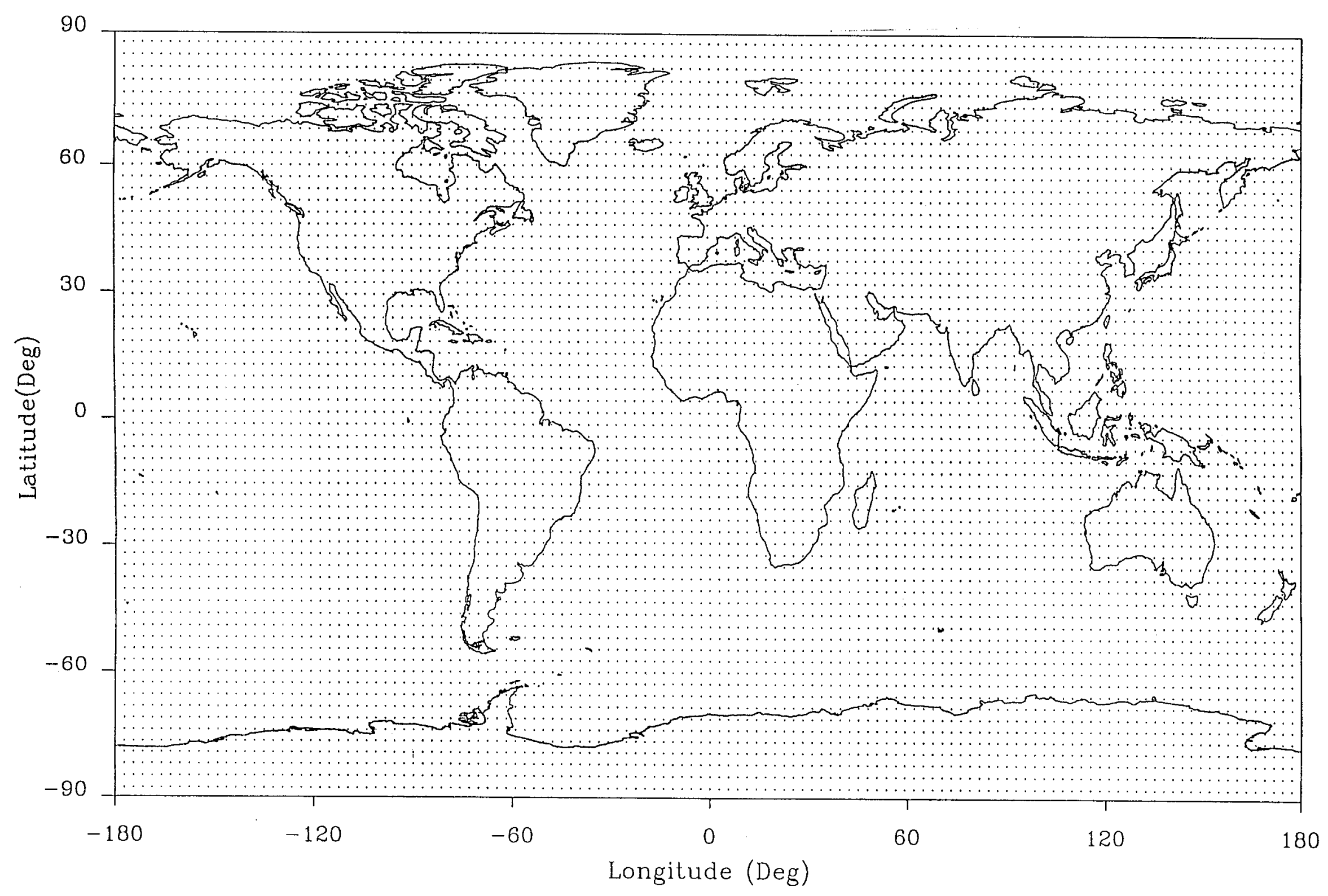

Figure 1 
Distribution of transponders at the $775 \mathrm{mb}$ pressure level after 1 day as a function of latitude and longitude for the uniform initial distribution case

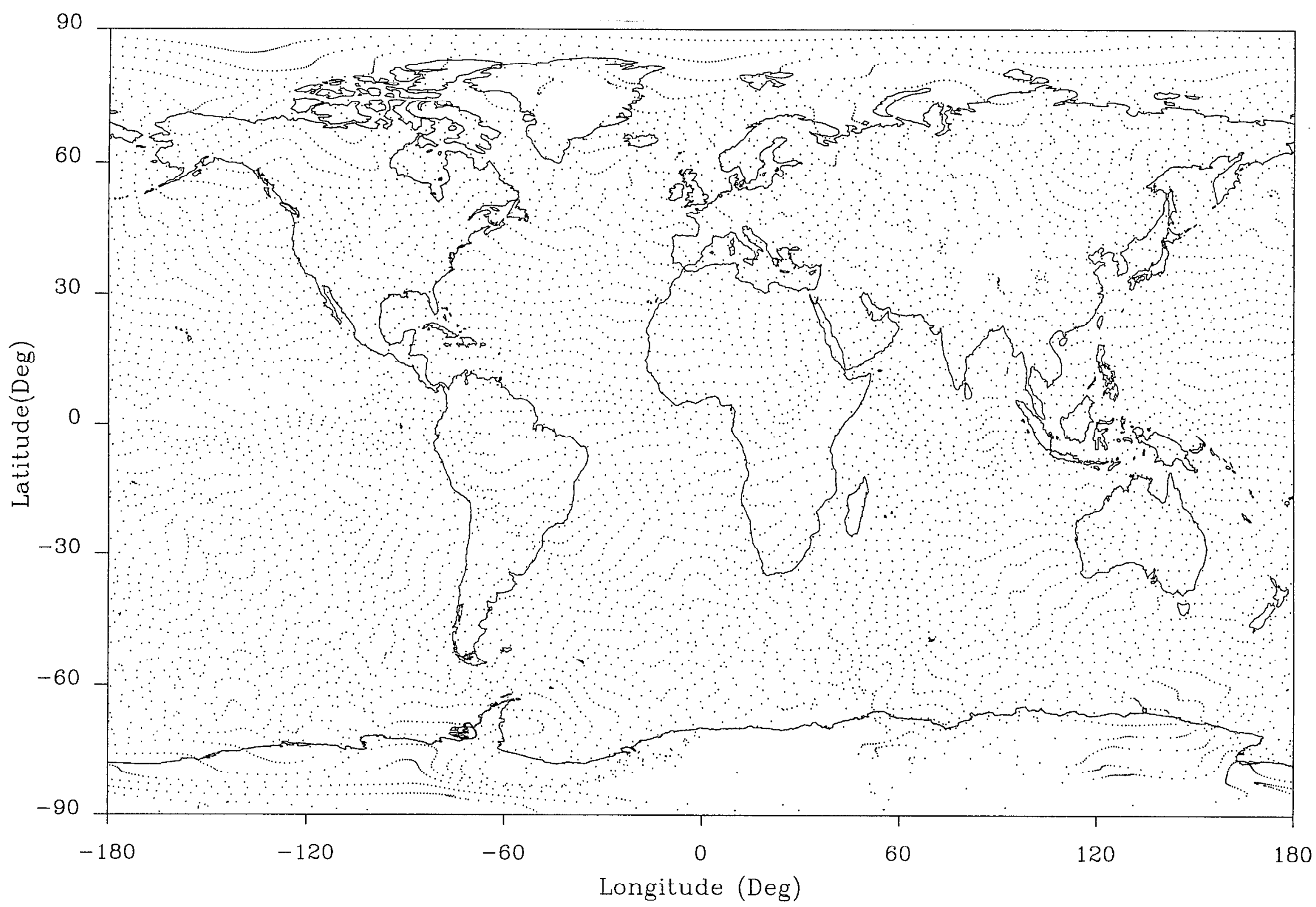

Figure 2 
Distribution of transponders at the $775 \mathrm{mb}$ pressure level after 10 days as a

function of latitude and longitude for the uniform initial distribution case

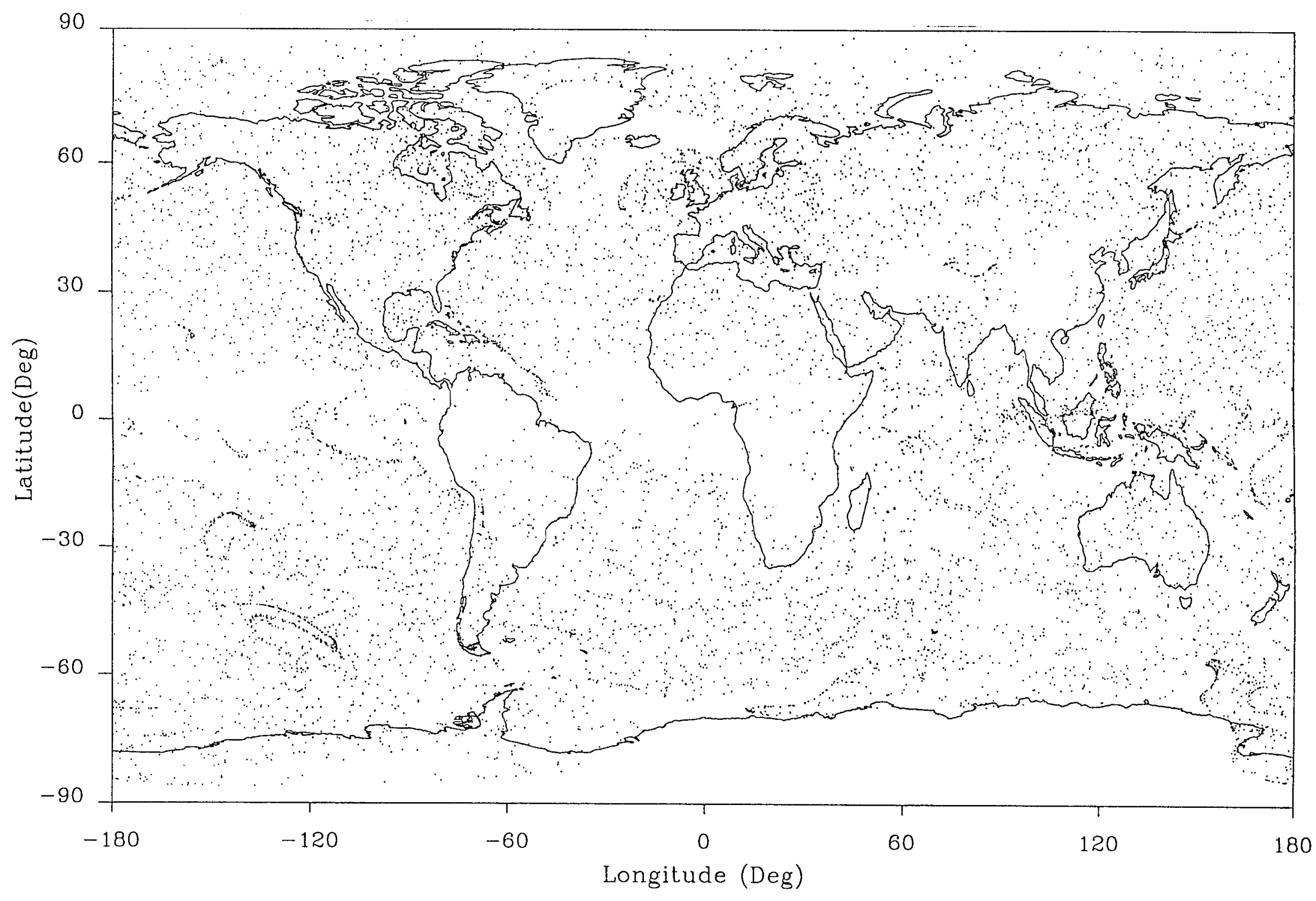

Figure 3 
Distribution of transponders at the $775 \mathrm{mb}$ pressure leve 1 after 35 days as a function of latitude and longitude for the uniform initial distribution case

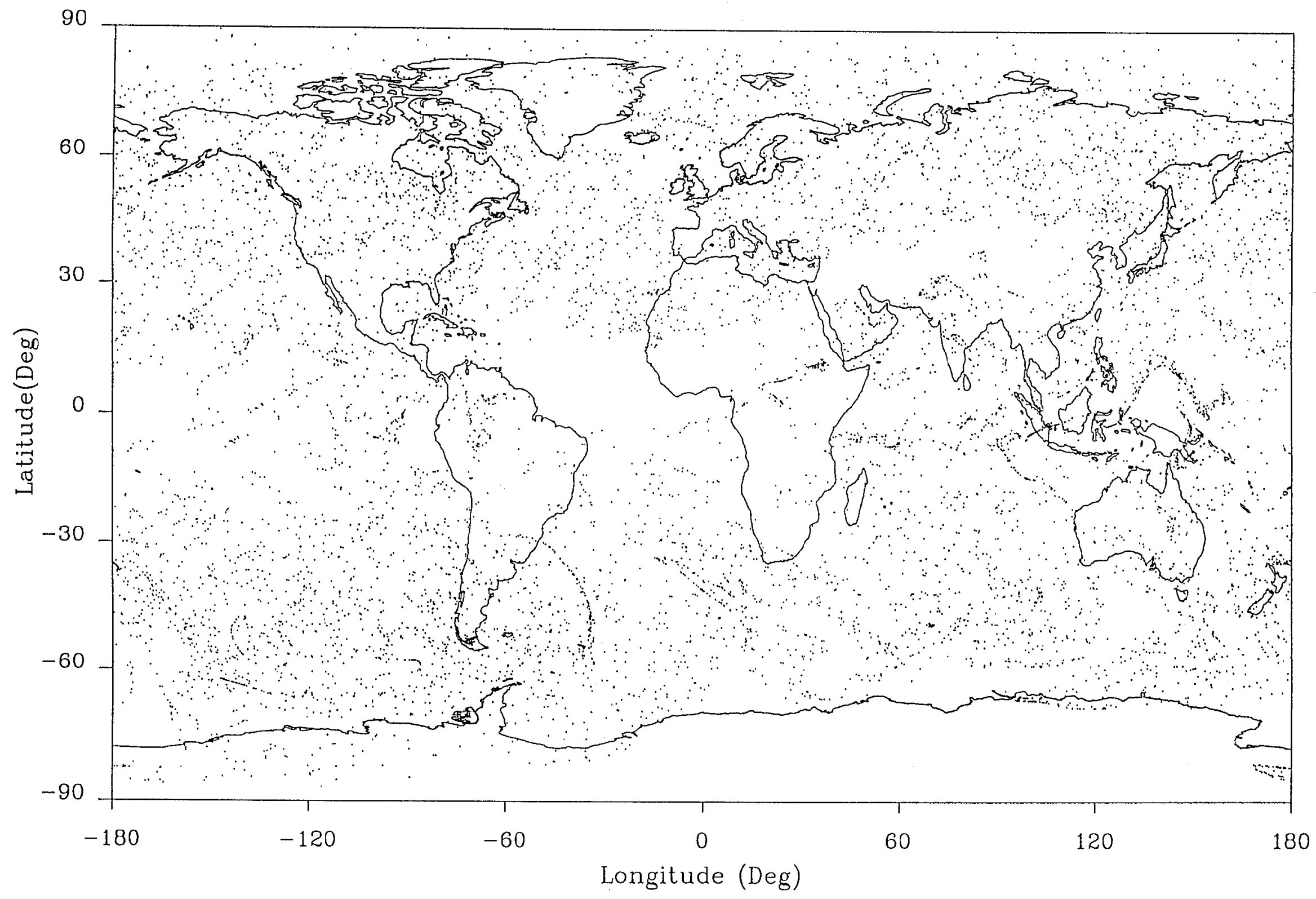

Figure 4 
Distribution of transponders at the $200 \mathrm{mb}$ pressure leve 1 after 1 day as a function of latitude and longitude for the uniform initial distribution case

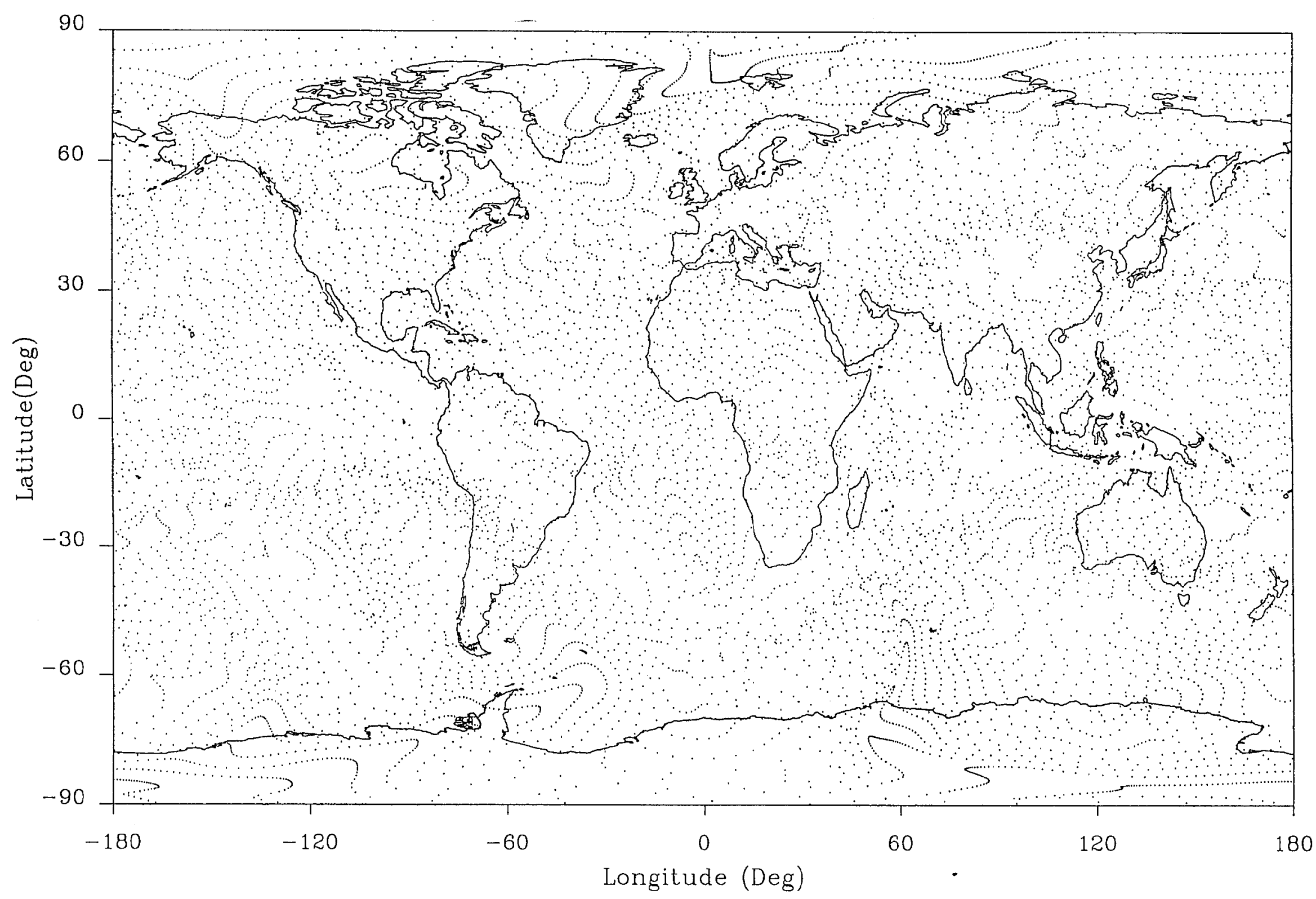

Figure 5 
Distribution of transponders at the $200 \mathrm{mb}$ pressure leve 1 after 10 days as

a function of latitude and longitude for the uniform initial distribution case

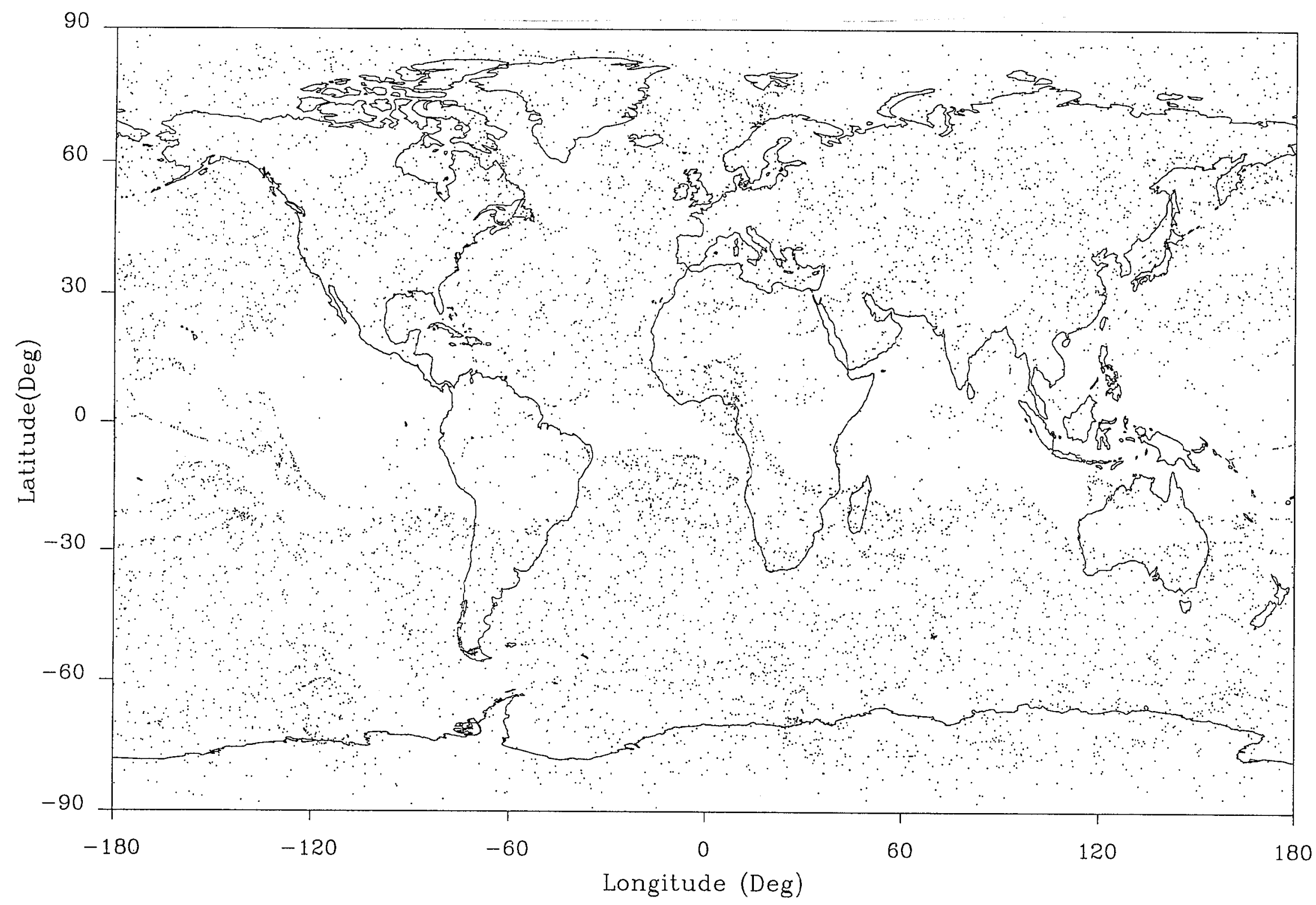

Figure 6 
Distribution of transponders at the $200 \mathrm{mb}$ pressure level after 35 days as a function of latitude and longitude for the uniform initial distribution case

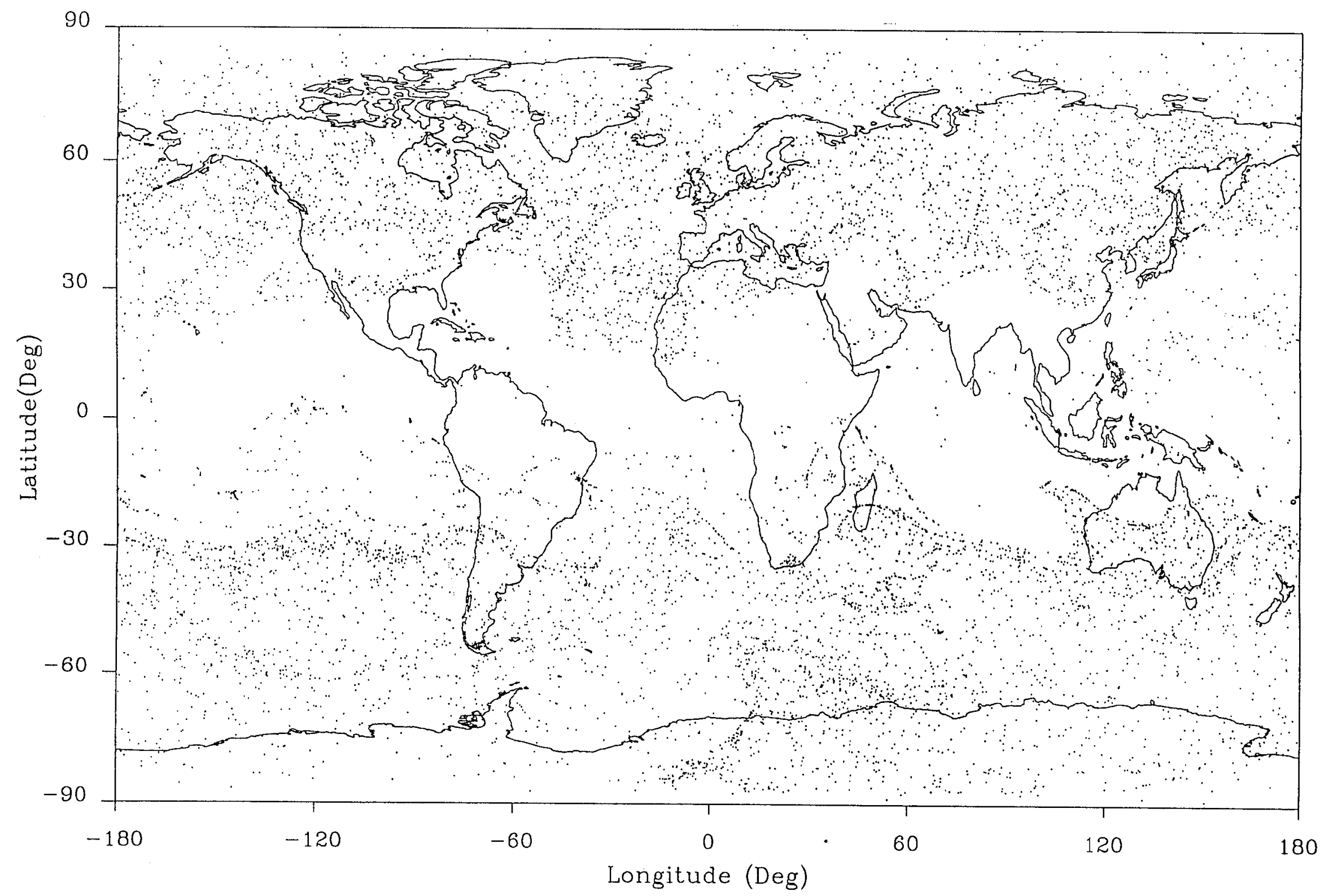

Figure 7 
Latitude-longitude map of transponder release sites for the 306 launch site, daily release study

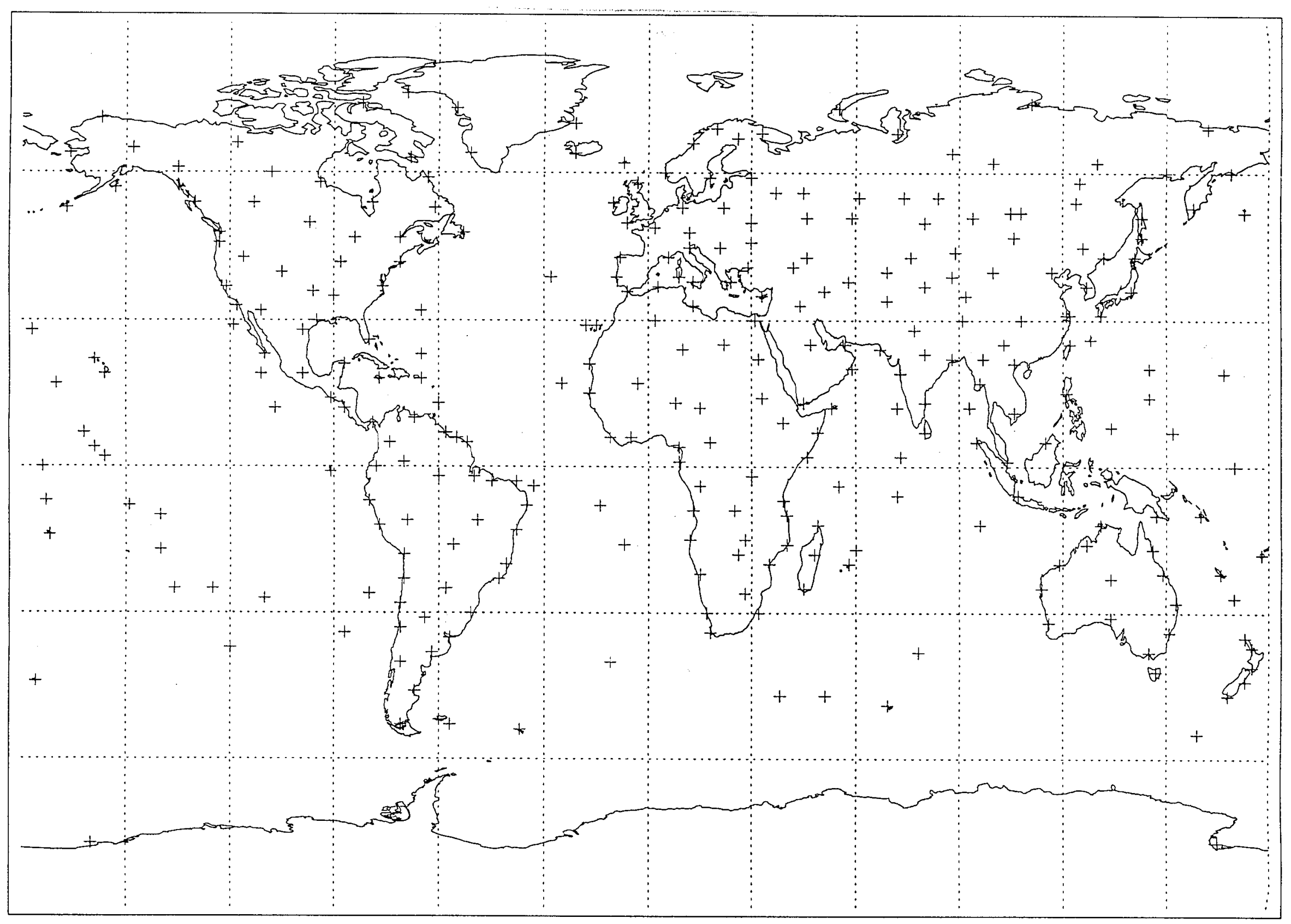

Figure 8 
Distribution of transponders at the $775 \mathrm{mb}$ pressure level after 35 days as a function of latitude and longitude for the 306 launch site, daily release study

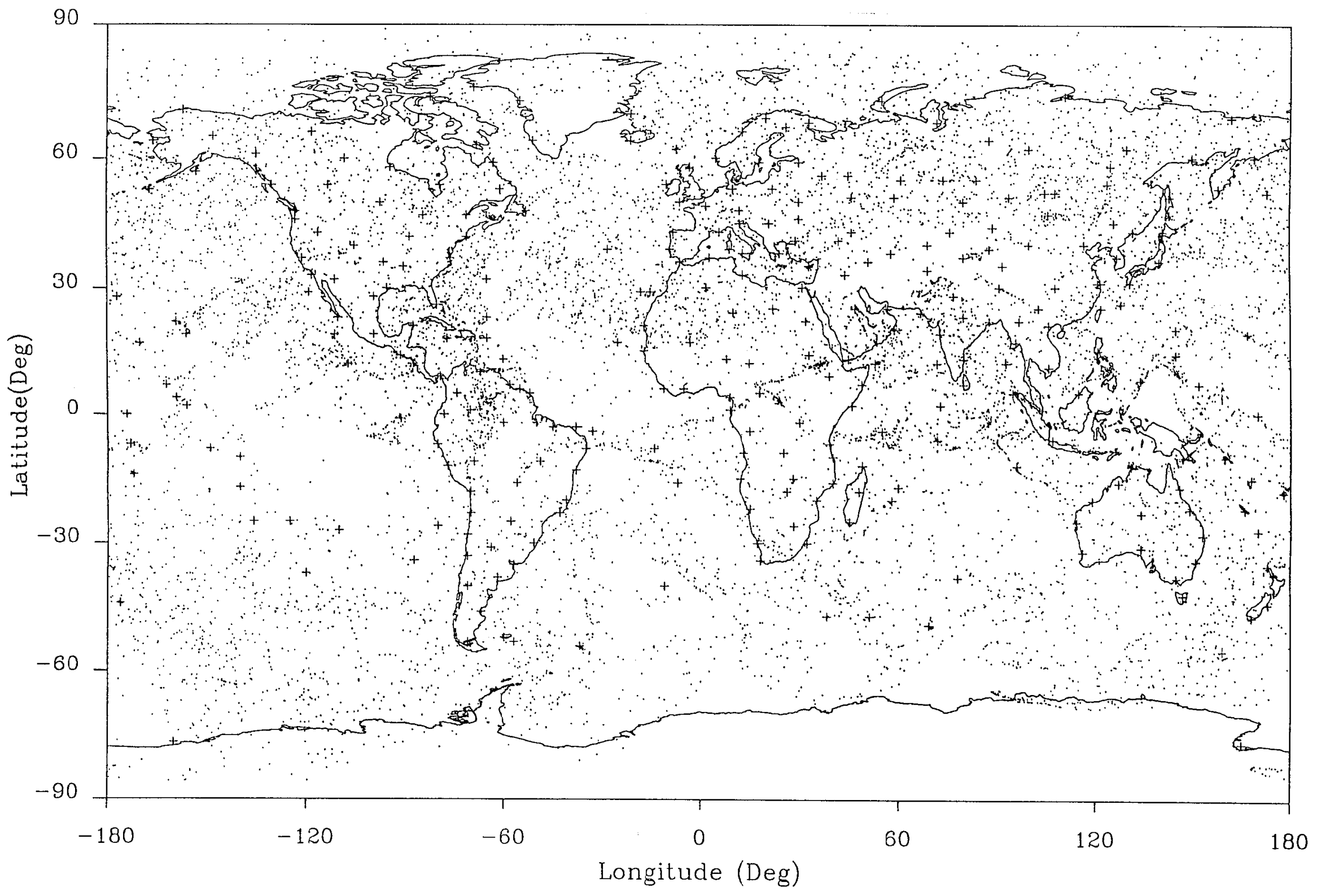

Figure 9 
Distribution of transponders at the $200 \mathrm{mb}$ pressure level after 35 days as a function of latitude and longitude for the 306 launch site, daily release study

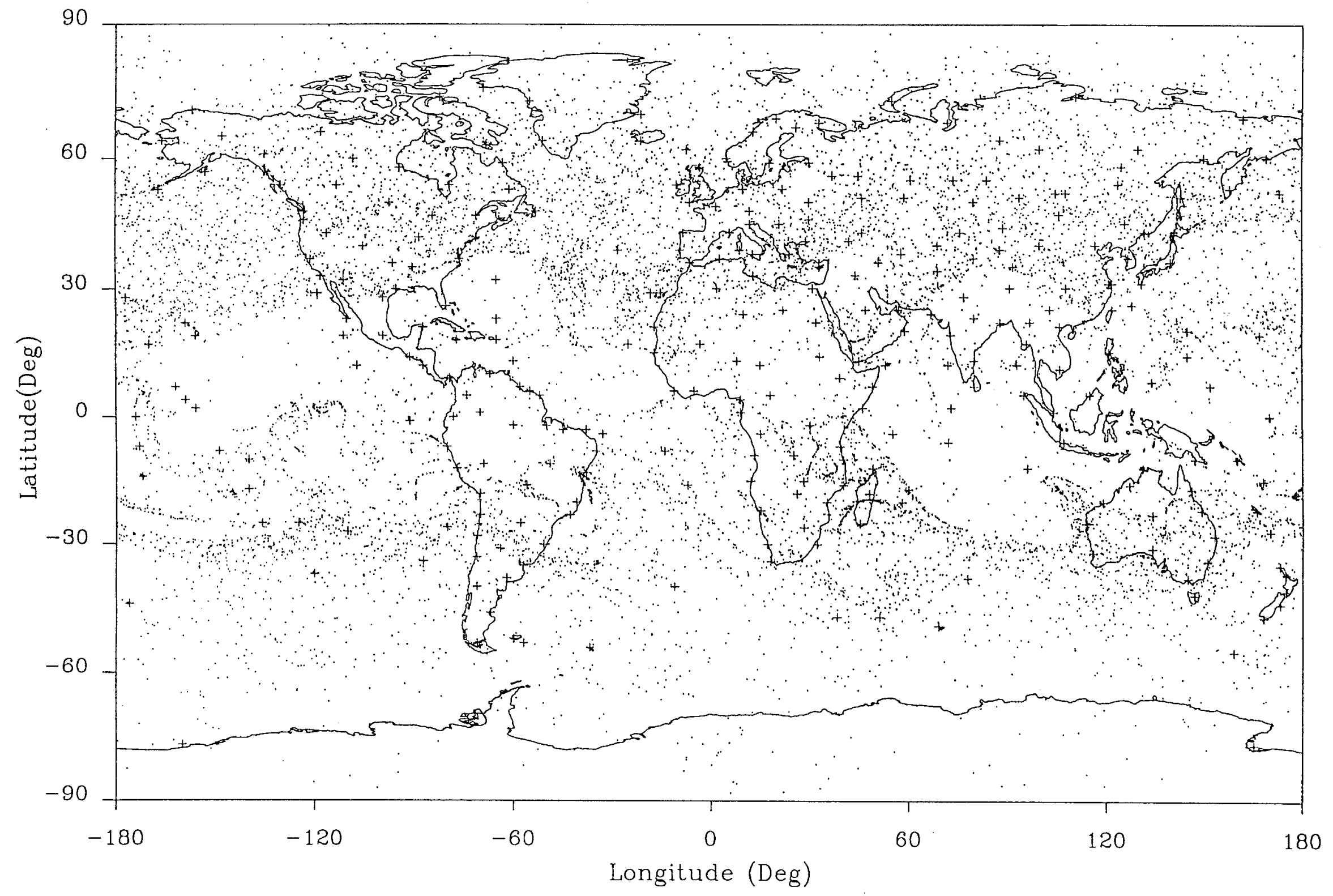

Figure 10 
Polar view of the measured trajectories of the GHOST Project balloons released at the $200 \mathrm{mb}$ pressure level from Christchurch, New Zealand

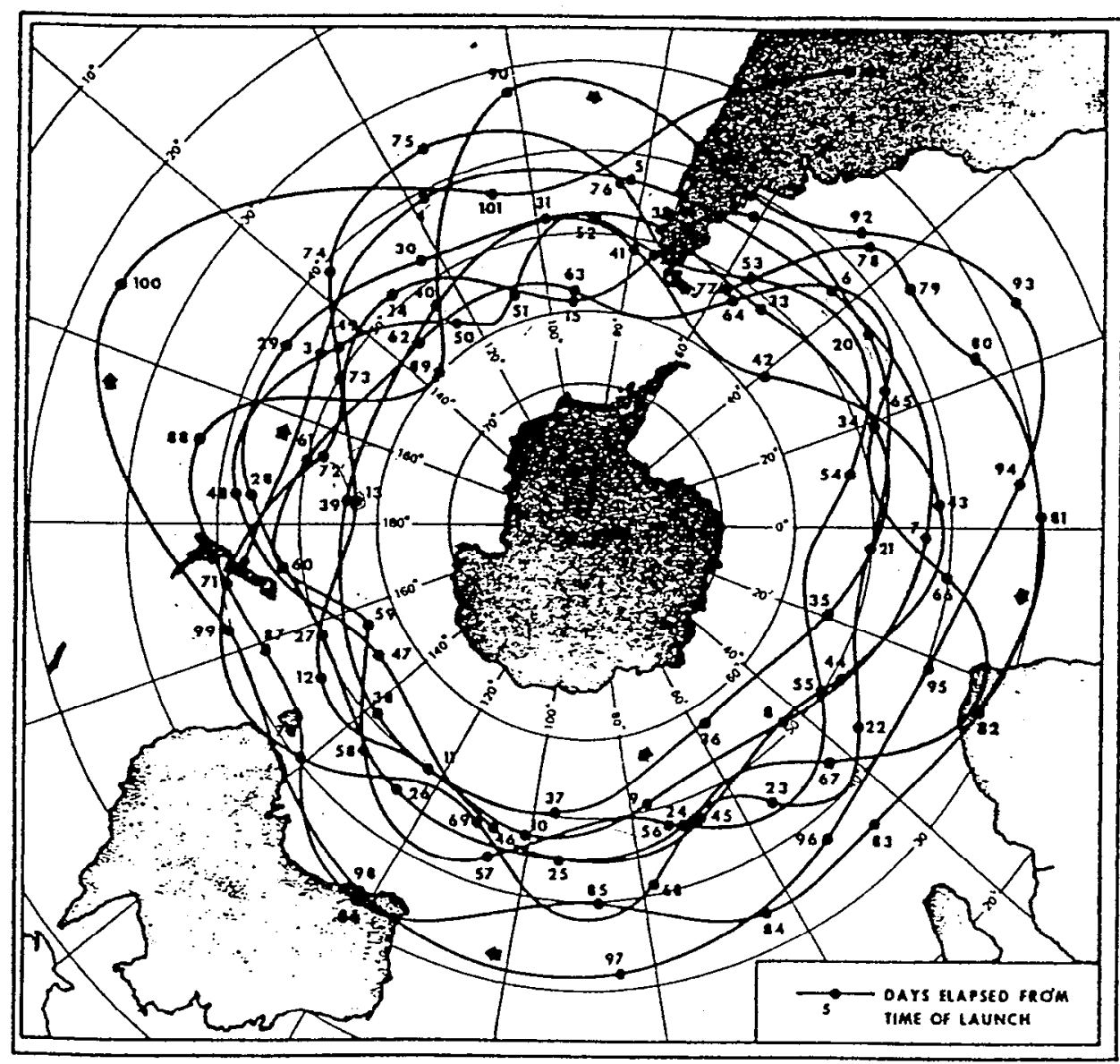

Fic. 1. Complete flight trajectory for Balloon No. 79R, launched from Christchurch, New Zealand. Flight level $200 \mathrm{mb}$.

Figure 11 
Polar view of the calculated trajectory of a transponder released at the $200 \mathrm{mb}$ pressure level from Christchurch, New Zealand on day 1

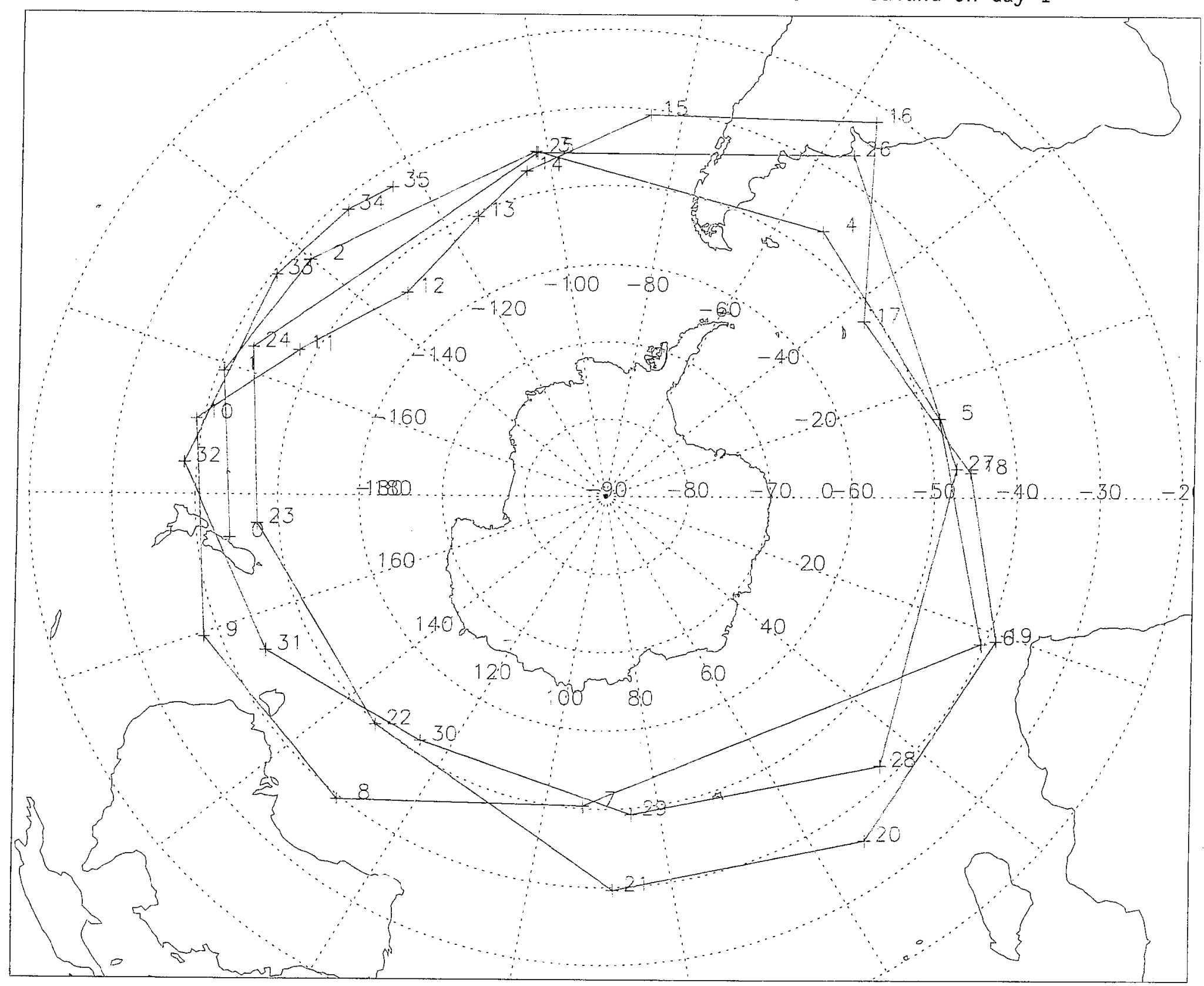

Figure 12 
Polar view of the calculated trajectory of a transponder released at the $200 \mathrm{mb}$ pressure level from Christchurch, New Zealand on Day 2

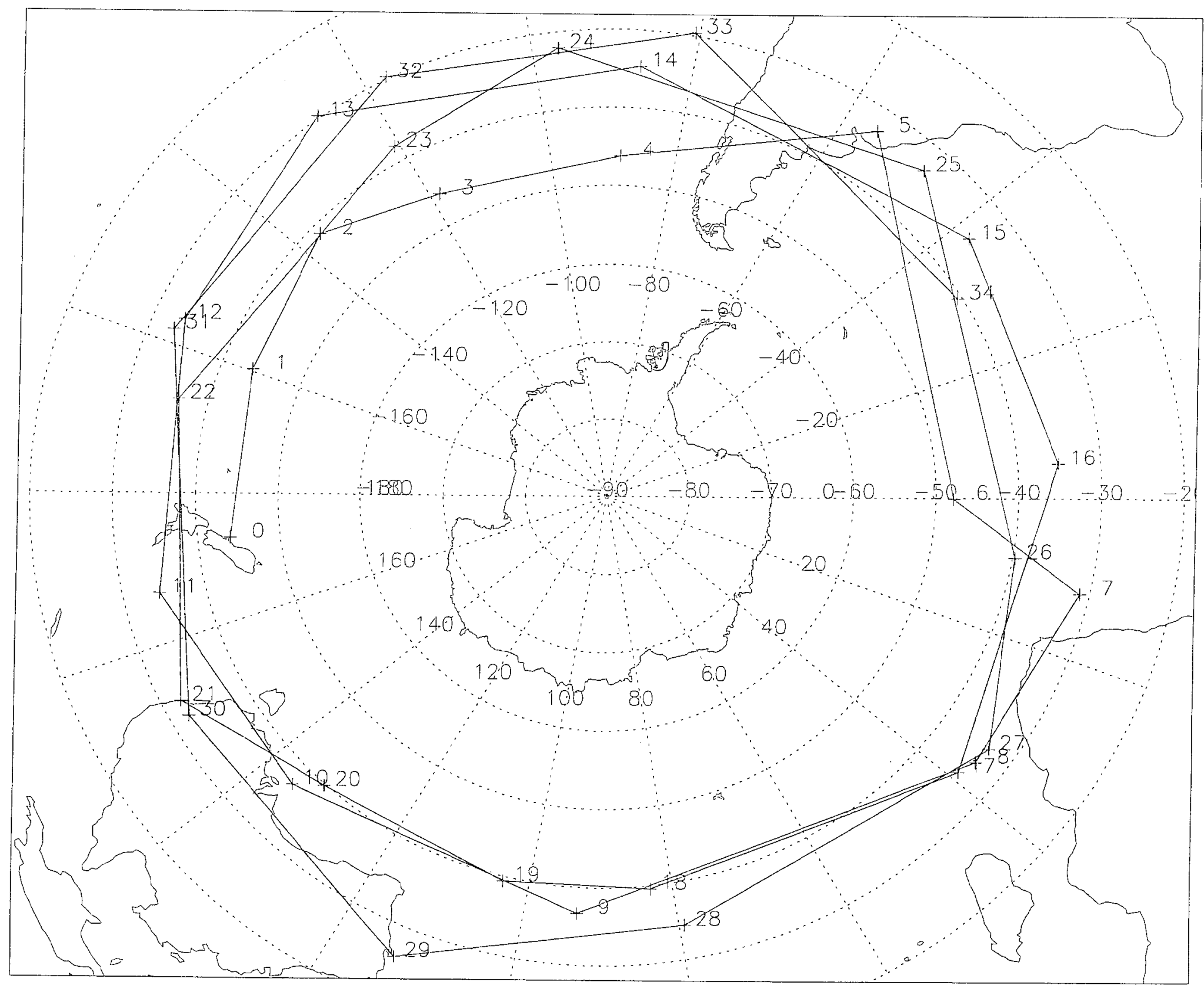

Figure 13 
Polar view of the calculated trajectory of a transponder released

at the $200 \mathrm{mb}$ pressure level from Christchurch, New Zealand on day 3

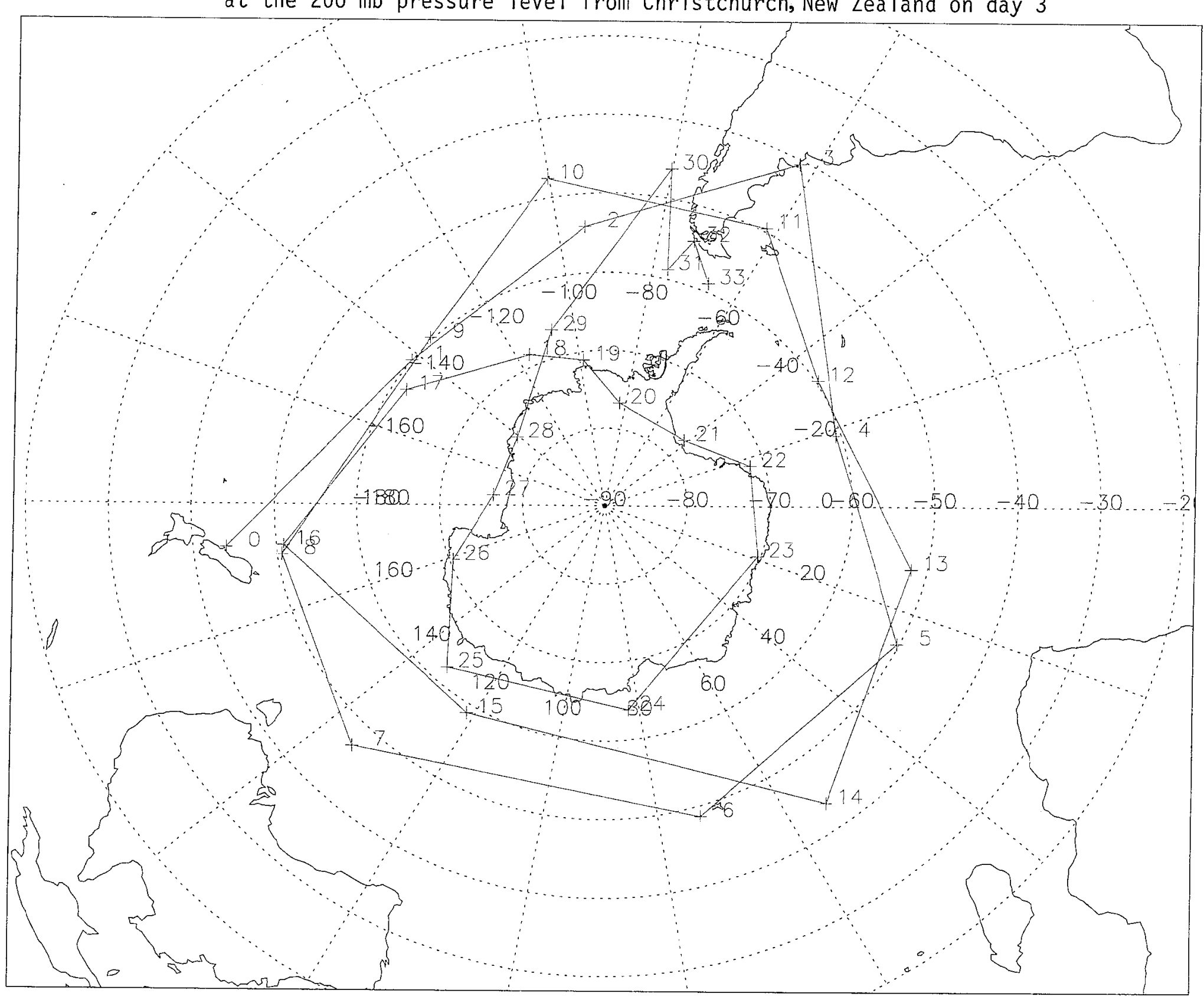

Figure 14 